Video Article / Video Makalesi

\title{
Transcatheter tricuspid valve-in-valve implantation in a dysfunctional bioprosthetic valve
}

\author{
Transkateter yolla disfonksiyonel biyoprotez kapak içine triküspit kapak implantasyonu
}

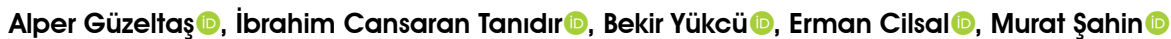 \\ Department of Pediatric Cardiology, Istanbul Mehmet Akif Ersoy Thoracic and Cardiovascular Surgery \\ Training and Research Hospital, Istanbul, Turkey
}

A 23-year-old female patient was being followed due to Ebstein anomaly since birth. Cone procedure was performed, when the patient reached 21 years old, due to the increased tricuspid valve insufficiency and New York Heart Association (NYHA) Functional Class IV. Valve insufficiency was considered mild-to-moderate postoperatively. One month after the operation, the patient referred to the hospital with heart failure and echocardiography revealed severe tricuspid valve insufficiency. A Pericarbon More ${ }^{\mathrm{TM}}$ stented biological valve (Sorin Group, Saluggia, Italy) No. 31 was surgically implanted in the tricuspid position and an epicardial pacemaker was implanted due to permanent atrioventricular block after surgery. Although tricuspid valve functions were good during the early postoperative period, valve functions were gradually deteriorated over time. Two years after surgery, transthoracic and transesophageal echocardiography revealed that one of the Pericarbon More ${ }^{\mathrm{TM}}$ valve leaflets was immobile, while the other leaflets were thickened, resulting in severe tricuspid valve insufficiency and moderate tricuspid valve stenosis (Video 1 and 2).

The patient was admitted to cardiac catheterization lab for transcatheter tricuspid valve-in-valve implantation. A 29-mm Edwards Sapien-XT ${ }^{\circledR}$ valve (Edwards Lifesciences Corp., CA, USA) was prepared with adding 2-cc extra volume to its balloon. The pacing rate of the epicardial pacemakers pacing rate increased to $180 \mathrm{bpm}$ during valve implantation into the tricuspid position (Video 3). Severe tricuspid valve insufficiency and stenosis were diminished after new valve implantation. Angiographic stenosis gradient decreased from $15 \mathrm{mmHg}$ to $5 \mathrm{mmHg}$, and the valve functions were good in the post-interventional period with no valvular insufficiency (Video 4 and 5).

In conclusion, transcatheter valve implantation into the bioprosthesis at the tricuspid valve position is an effective method for reducing the number of repetitive surgical interventions..$^{[1-3]}$

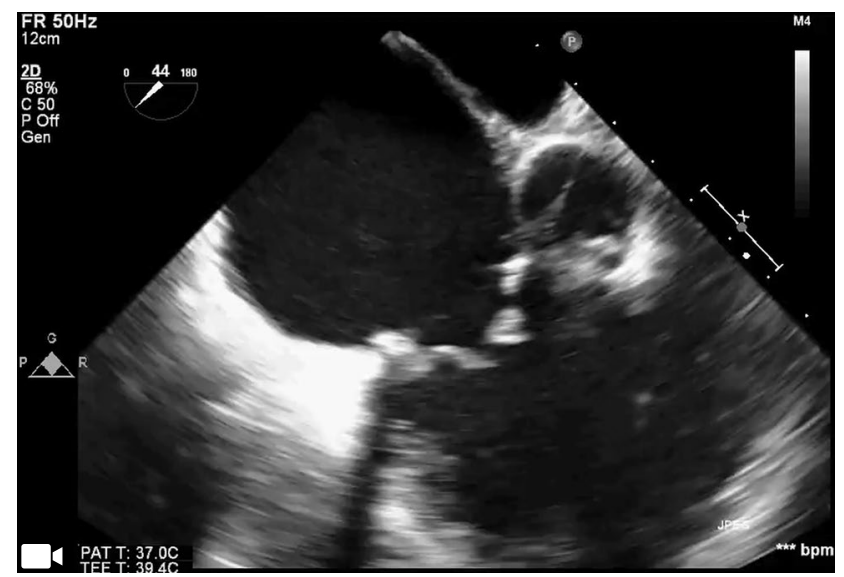

Video 1. Transesophageal and transthoracic echocardiography prior to intervention showing one of the bioprosthetic valve leaflets not moving and other leaflets thickened. Severe prosthetic valve insufficiency and moderate prosthetic valve stenosis.

Received: September 08,2020 Accepted: December 25, 2020 Published online: April 26, 2021

Correspondence: Alper Güzeltaş, MD. İstanbul Mehmet Akif Ersoy Göğüs Kalp ve Damar Cerrahisi Eğitim ve Araştırma Hastanesi, Çocuk Kardiyoloji Kliniği, 34303 Küçükçekmece, İstanbul, Türkiye. Tel: +90 542 - 2560601 e-mail: alperguzeltas@hotmail.com Cite this article as:

Güzeltaş A, Tanıdır iC, Yükcü B, Cilsal E, Şahin M. Transcatheter tricuspid valve-in-valve implantation in a dysfunctional bioprosthetic valve Turk Gogus Kalp Dama 2021:29(2):290-291 


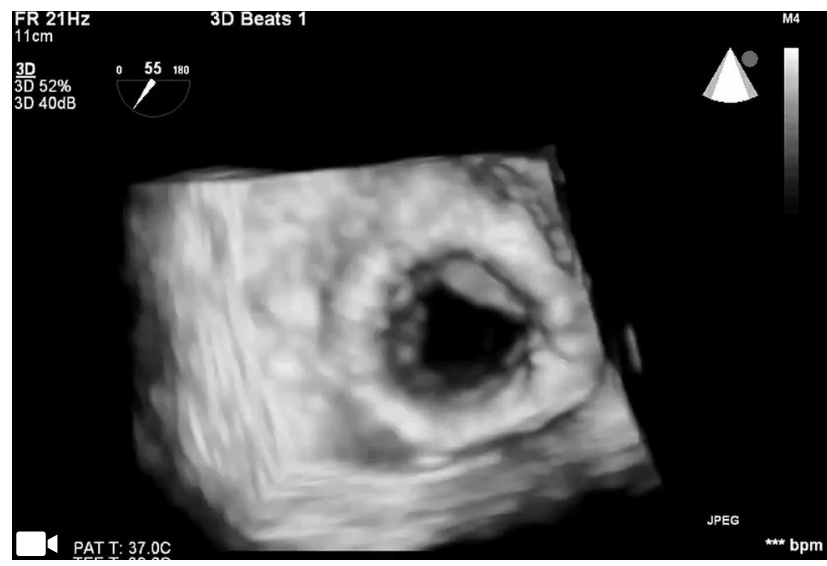

Video 2. Three-dimensional transesophageal echocardiography showing one of the bioprosthetic valve leaflet not moving.

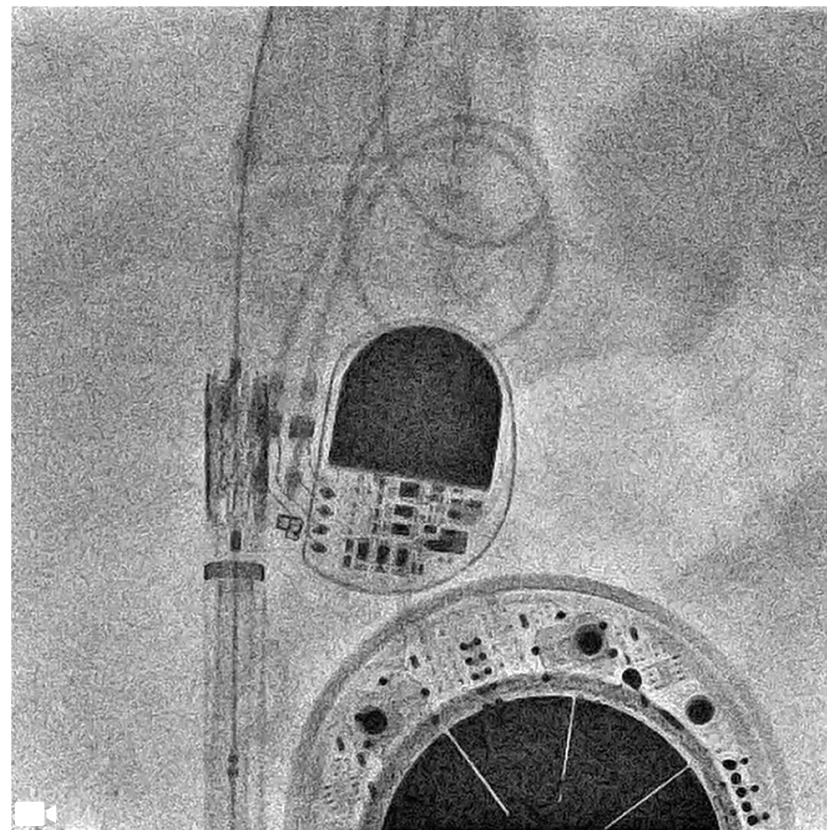

Video 3. Transcatheter valve-in-valve implantation with Edwards Sapien $X T^{\circledR}$ valve into the tricuspid position. Heart rate increasing to $180 \mathrm{bpm}$ with epicardial pacemaker pacing while inflating the balloon to ensure valve stabilization.

\section{Declaration of conflicting interests}

The authors declared no conflicts of interest with respect to the authorship and/or publication of this article.

\section{Funding}

The authors received no financial support for the research and/or authorship of this article.

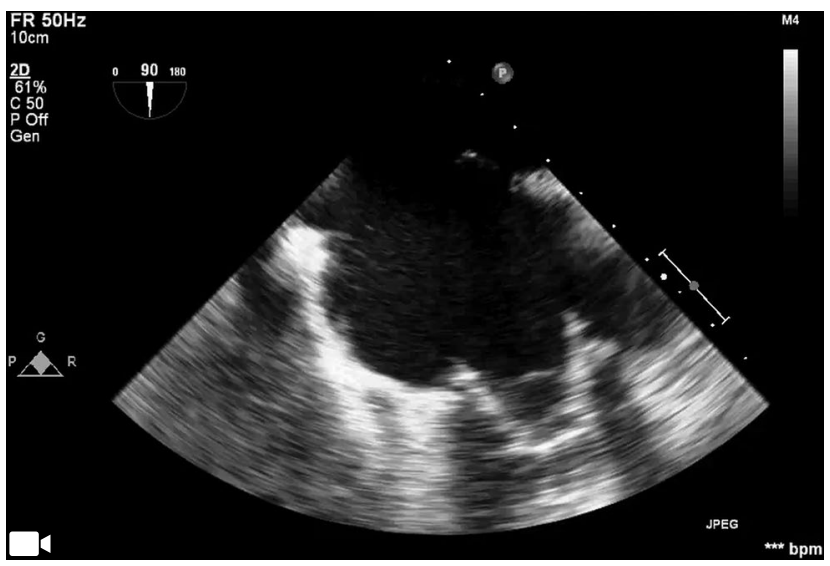

Video 4. Transesophageal and transthoracic echocardiography after surgery showing the movements of Edwards Sapien $\mathrm{XT}^{\circledR}$ valve. No insufficiency in color Doppler imaging.

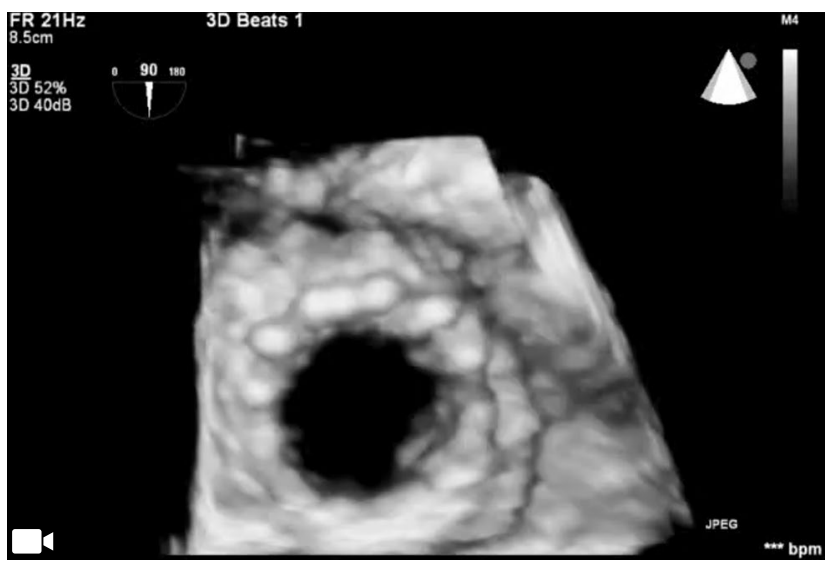

Video 5. Three-dimensional transesophageal echocardiography showing normal valve functions of Edwards Sapien $\mathrm{XT}^{\circledR}$ after the procedure.

\section{REFERENCES}

1. Gaia DF, Palma JH, de Souza JA, Buffolo E. Tricuspid transcatheter valve-in-valve: An alternative for high-risk patients. Eur J Cardiothorac Surg 2012;41:696-8.

2. McElhinney DB, Cabalka AK, Aboulhosn JA, Eicken A, Boudjemline Y, Schubert S, et al. Transcatheter tricuspid valve-in-valve implantation for the treatment of dysfunctional surgical bioprosthetic valves: An International, Multicenter Registry Study. Circulation 2016;133:1582-93.

3. Sanon S, Cabalka AK, Babaliaros V, Rihal C, Gafoor $\mathrm{S}$, Webb J, et al. Transcatheter tricuspid valve-in-valve and valve-in-ring implantation for degenerated surgical prosthesis. JACC Cardiovasc Interv 2019;12:1403-12. 